\title{
Metoda Maternal Reflektif (MMR) untuk Meningkatkan Kemampuan Bahasa Lisan Anak Tunarungu
}

\author{
Zulmiyetri \\ Universitas Negeri Padang \\ $\risingdotseq$ e-mail: yetrizulmiyetri@gmail.com
}

\begin{abstract}
Abstrak
Kemampuan berbahasa lisan anak tunarungu sering mengalami gangguan dalam kelas IV yang berjumlah 4 orang. Hasil penelitian pada siklus pertama dengan pengucapan dan berkomunikasi, sehingga anak lebih suka berbahasa isyarat daripada berbahasa secara verbal. Hal ini disebabkan kosakata yang dimiliki anak tunarungu sangat kurang. Penelitian ini bertujuan untuk memperoleh gambaran yang jelas tentang peningkatan kemampuan berbahasa lisan anak tuna rungu dengan menggunakan Metode Maternal Reflektif (MMR).Metode yang digunakan dalam penelitian ini adalah Metode Penelitian Tindakan Kelas, dengan berkolaborasi antara peneliti dan guru kelas. Penelitian ini dirancang melalui 1) perencanaan. 2) tindakan 3) Observasi dan 4) refleksi. Subjek peneltian ini terdiri dari siswa tunarungu menggunakan Metode Maternal Reflektif terhadap keempat anak tunarungu belum sepenuhnya berhasil dengan baik, hal ini disebabkan anak masih mengalami hambatan dalam berbahasa lisan. Sedangkan pada siklus kedua kemapuan lisan pada anak tunarungu telah meningkat dengan baik. Karena pada siklus ini diberikan perlakuan secara individual, dengan menggunakan media yang menarik sehingga keempat anak tunarungu pada penelitian ini telah dapat berbahasa lisan dengan baik. Hasil penelitian menunjukkan bahwa dengan menggunakan Metode Maternal Reflektif secara individual dan penggunaan media yang menarik maka kemampuan berbahsa lisan anak tunarungu mengalami peningkatan. Dari hasil penelitian tersebut dapat disimpulkan bahwa bahasa lisan anak tunarungu dapat ditingkatkan dengan menggunakan Metode Maternal Reflektif. Disarankan kepada guru-guru di SLB agar sering melatih anak berbahasa lisan dengan menggunakan Metode Maternal Reflektif untuk yang mengalami gangguan berbahasa lisan.
\end{abstract}

Kata Kunci: metoda maternal reflektif , bahasa lisan, anak tunarungu

Copyright (C) 2017 IICET (Indonesia) - All Rights Reserved

Indonesian Institute for Counseling, Education and Therapy (IICET)

\section{PENDAHULUAN}

Kemampuan berbahasa khususnya bahasa lisan sangat diperlukan (Setyawati, R. 2013; Fajri, R. A. S. 2015; Suci, E. R. 2013) untuk memahami pendidikan dan mengadakan komunikasi dengan lingkungan yang lebih luas. Kemampuan berbahasa anak tunarungu harus dilatih sedini mungkin (Savitri, V. 2016; Putri, Y. M. 2014), terutama latihan bicara agar kemampuan berbahasa lisan anak dapat ditingkatkan seoptimal mungkin. Kemampuan berbahasa anak dapat dikembangkan (Hernawati, T. 2007; Khobir, A. 2013, May) dan untuk pengembangannya diperlukan metode pengajaran yang tepat dan sesuai dengan karakteristik anak. Salah satu metode yang dapat digunakan untuk meningkatkan bahasa lisan anak tunarungu adalah Metode Maternal Reflektif (MMR) (Pujiwati, S. 2012; Siti Walidatul, A. 2014).

Bahasa merupakan alat komunikasi yang utama dalam kehidupan manusia. Sebagai alat komunikasi, bahasa merupakan saluran perumusan tujuan, melahirkan perasaan, memungkinkan kita menciptakan kerja sesama warga dan mengatur berbagai aktifitas kemasyarakatan serta merencanakan masa depan. Bahasa juga memungkinkan manusia menganalisa masa lampau untuk memetik hasil-hasil yang berguna bagi masa 
sekarang dan masa datang. Karena itu jelaslah bahwa bahasa merupakan saran komunikasi yang vital dan harus dikuasai manusia.

Pada hakekatnya manusia sebagai makhluk sosial cenderung untuk hidup berkelompok dan berinteraksi satu sama lainnya. Oleh karena itu manusia dituntut agar dapat menguasai bahasa yang dipergunakan untuk menyampaikan informasi kepada manusia lain. Sebelum menguasai bahasa manusia mendengar terlebih dahulu bahasa yang diucapkan orang lain. Selain itu manusia meniru apa yang didengarnya dan mengucapkan kembali dengan menggerakkan organ-organ bicara yang diperlukan untuk mengungkapkan bahasa yang dikuasainya. Disamping menguasai bahasa, anak juga harus memahami konsep dari bahasa itu sendiri,sehingga penyampaian informasi dapat dilakukan dengan baik dan berjalan dengan lancar.

Interaksi dalam proses belajar mengajar merupakan salah satu cara perolehan bahasa yang dilakukan antara dua orang atau lebih untuk bertukar fikiran, menyampaikan pesan, ide atau gagasan sehingga bahasa yang dimaksud dapat dipahami. Salah satu tujuan khusus pembelajaran, terutama dalam pembelajaran bahasa Indonesia untuk anak tunarungu sama dengan tujuan khusus pengajaran bahasa untuk anak normal pada umumnya. Dalam pengajaran bahasa Indonesia titik berat pengajarannya adalah mencakup empat keterampilan berbahasa, yaitu mendengar, berbicara, menulis dan apresiasi sastra.

Anak tunarungu adalah anak yang mengalami kekurangan atau kehilangan kemampuan (Hasanah-Nim, U. S. W. A. T. U. N. 2010) mendengar sebahagian atau seluruh pendengarannya, sehingga tidak mampu mendengar, mengungkapkan kata-kata dan berbicara dengan orang lain. Ini adalah akibat dari tidak adanya masukan bunyi suara atau pesan yang diterima oleh anak tunarungu, sehingga alat bicaranya tidak terlatih atau digunakan untuk mengungkapkan kembali kata-kata yang diungkapkan orang lain. Hal ini menjadikan alat bicaranya anak tunarungu menjadi kaku. Kaku disini artinya mereka mengalami kesulitan untuk mengungkapkan sesuatu tanpa latihan bicara, karena alat bicaranya tidak dapat bergerak secara otomatis melainkan harus dieja Somat dan Hemawati, 1996:139).

Bahasa merupakan hal penting dalam berkomunikasi, akan tetapi komunikasi anak tunarungu lebih cenderung menggunakan bahasa isyarat terutama bahasa ibu. Ini disebabkan kurangnya penguasaan kosakata yang dimiliki oleh anak. Sementara anak tunarungu dalam bergaul dan bersosialisasi dengan lingkungan membutuhkan bahasa lisan atau dituntut berbahasa lisan. Dan kondisi anak tunarungu tersebut maka penulis mengadakan diskusi dengan guru kelas tentang ketidak berhasilan anak tunarungu dalam berbahasa lisan. Saya sebagai peneliti dan guru kelas akan mencoba menerapkan pengunaan MMR dalam pengajaran bahasa lisan. Karena dengan MMR anak tunarungu dituntut untuk lebih banyak berbicara atau bercakap secara alami/natural dengan teman atau guru.Penelitian ini bertujuan untuk meningkatkan kemampuan berbahasa lisan anak tunarungu dengan menggunakan MMR.

Tuna artinya kurang (Fitrianingsih-Nim, E. N. I. 2011; Virlia, S., \& Wijaya, A. 2015), sedangkan rungu artinya pendengaran (Yuliana, D. W., \& Supraptono, E. 2016; Lisa, A. Y. 2012). Menurut Halahan dan JH Kauffman (dalam Somat dan Hemawati, 1996) mengatakan bahwa "Tunarungu adalah suatu istilah umum yang menunjukkan kesulitan mendengar yang meliputi keseluruhan kesulitan mendengar dari yang ringan sampai yang berat, digolongkan pada bagian tuli dan kurang dengar". Orang tuli adalah orang yang kehilangan kemampuan mendengar sehingga menghambat proses informasi bahasa melalui pendengaran, baik memakai ataupun tidak memakai alat bantu dengar. Sedangkan seseorang yang kurang dengar adalah seseorang yang biasanya menggunakan alat bantu dengar. Sisa pendengarannya cukup memungkinkan keberhasilan proses informasi bahasa melalui pendengaran.

Adapun beberapa hal yang perlu diperhatikan guru sebelum memberikan latihan atau pengajaran berbahasa lisan kepada anak tunarungu, sebagaimana yang dikemukakan oleh Somad dan Hemawati (1995), yaitu : (1) adanya kemampuan anak untuk melakukan gerakan organ bicara meskipun dengan sederhana, (2) IQ anak diatas 70 atau tergolong anak yang mampu didik, (3) lingkungan keluarga harus bersikapkooperatif, sehingga memungkinkan anak untuk mendapatkan rangsangan positif dan kesempatan di dalam pembentukan konsep bahasa.

Sedangkan MMR adalah Metode Maternal Reflektif merupakan suatu bentuk teknik pengajaran yang mengutamakan percakapan sebagai poros kegiatan belajar mengajar dengan ditunjang oleh metode tangkap dan peran ganda dari guru. Menurut Leni Bunawan dan Yuwati (2000) MMR adalah: "Suatu metode 
pengajaran bahasa yang mengikuti cara-cara anak mendengar sampai pada penguasaan bahasa ibu dan menuntut anak agar secara bertahap mampu menemukan sendiri aturan atau bentuk bahasa melalui refleksi terhadap segala pengalaman berbahasanya".MMR merupakan percakapan antara dua orang atau lebih yang bersifat pertukaran gagasan, informasi, perasaan atau fikiran untuk pengajaran bahasa sewajar mungkin pada anak tunarungu.

Tujuan Metode Maternal Reflektif Dalam menggunakan percakapan tidak hanya sekedar sarana/media untuk penyampaian materi pelajaran, tetapi juga percakapan yang menjadi tujuan pengajaran.Menurut Bunawan dan Yuwati (2000) tujuan MMR adalah sebagai berikut: (1) belajar untuk bersikap spontan untuk mengungkapkan isi hati, mengatakan keinginan, maksud keheranan, kegembiraan, kesedihan, permintaan maaf, keingintahuan dan sebagainya, (2) belajar untuk bersikap reaktif terhadap ungkapan isi hati lawan bicara, menyanggah, membenarkan, menanyakan, menjawab pertanyaan dan sebagainya, (3) belajar berempati, yaitu masuk ke dalam perasaan orang lain.

Langkah-langkah Pelaksanaan MMR: Menurut Yuwati (1998) mengatakan bahwa penerapan MMR dapat disimpulkan sebagai berikut: Anak yang belum berbahasa, kegiatan Ini mencakup: Percakapan antara guru atau pelatih berlangsungsecara spontan, dan terjadi kapan saja, dimana saja serta tentang apa saja. Hal yang dipercakapkan oleh guru atau pelatih dengan anak tunarungu mengenai hal yang menarik dan sedang dialami oleh anak. Kemampuan membaca anak masih dalam taraf ideovisual, maksudnya anak tunanrungu hanya dapat membaca melalui gambar-gambar atau balon-balon percakapan. (d) Guru atau pelatih memegang peran ganda, yaitu sebagai guru atau sebagai pelatih bagi anak tunarungu. Dengan kata lain guru atau pelatih pada saat mengajar dengan Metode Maternal Reflekttf memainkan peran sebagai guru atau sebagai pelatih dengan cara guru mengulangi kembali ungkapan atau bicara anak dan kemudian menanggapi. Anak yang sudah berbahasa. Langkah-langkah pelaksanaan percakapan membaca ideovisual. a) Guru membimbing anak membaca kalimat demi kalimat dengan memperhatikan frase-frasenya.

Guru mempercakapkan isi bacaan dengan beberapa kunci pertanyaan. Pokok-pokok pertanyaan menggunakan kata-kata tanya seperti apa, siap, berapa, kapan, dimana, mengapa (apa sebab), b) Kata-kata benda, kelompok atau kalimat hendaknva diolah dengan permainan identifikasi, c) Kata-kata sifat diolah dengan menggunakan prinsip kontras, d) Kata-kata keterangan tempat dan keterangan waktu harus diolah dengan prinsip kontras juga, e) Setelah selesai mengolah bacaan atau setelah anak memahami bacaan secara global intuitif, guru melanjutkan dengan latihan terhadap salah satu aspek kebahasaan. Penelitian ini bertujuan untuk : 1) untuk mengetahui proses penerapan Metode Maternal Reflektif dalam meningkatkan kemampuan bahasa lisan anak tunarungu 2) untuk membuktikan apakah Metode Maternal Reflektif dapat meningkatkan bahasa lisan anak tunarungu.

\section{METODOLOGI}

Penelitian ini menggunakan metode Penelitian Tindakan Kelas (action research) (Mertler, C. A. 2008; Stringer, E. T. 2008). Menurut Hardjodipuro (1997) action research adalah penetitian yang bersifat partisipatif dan kolaboratif yaitu penelitian vang dilakukan sendiri oleh yang berkepentingan yaitu peneliti dan diamati bersama-sama dengan rekannya (Kemmis, S., McTaggart, R., \& Nixon, R. 2013; Greenwood, D. J., Whyte, W. F., \& Harkavy, I. 1993).

Secara umum penelitian tindakan ini ditujukan untuk membuat suatu perubahan berupa peningkatan pengetahuan yang menyangkut suatu pemecahan terhadap persoalan antara teori dan praktek yang dihadapi oleh para guru di sekolah. Selanjutnya Suyatno (1997) mengemukakan bahwa ada empat bentuk penelitian tindakan kelas yaitu: “(1) Penelitian tindakan kelas guru sebagai peneltti, (2) Penelitian tindakan kelas kolaboratif, (3) Penelitian tindakan kelas sirnultan terintegrasi, (4) Penelitian tindakan kelas administrasi sosial eksperimen".

Sesuai dengan bentuk-bentuk penelitian tindakan kelas vang dikemukakan diatas.maka penelitian ini menggunakan bentuk penelitian tindakan kelas kolaboratif. Dan penelitian ini memerlukan pihak-pihak lain yang terkait, peneliti berkolaborasi dengan guru kelas dimulai dari perumusan masalah sampai kepada pelaporan hasil penelitian kelas.Hubungan antara guru dan peneliti berbentuk kemitraan, sehingga mereka memikirkan masalah-masalah penelitian secara bersama pula. 


\section{HASIL DAN PEMBAHASAN}

Setelah peneliti melakukan penelitian berupa tindakan sebanyak 20 kali pertemuan dengan dua siklus dan masing-masing siklus sebanyak 10 kali pertemuan.Untuk dapat mengetahui bagaimanakah upaya yang telah dilakukan dalam meningkatkan kemampuan berbahasa lisan melalui Metode Maternal Reflektif.Pada anak tunarungu kelas dasar $\mathrm{V}$, peneliti melakukakn pengamatan dan penilaian terhadap ungkapan bahasa, penguasaan kosa kata, pengenalan struktur kalimat, makna kata, intonasi dan kelancaran suara yang dinilai pada tiap pertemuan.

Berpedoman pada kegiatan siklus demi siklus dan pertemuan demi pertemuan dalam tiap tema, dapat dilihat kemajuan yang diperoleh. Pada tema satu (transportasi) awalnya siswa masih menggunakakan bahasa isyarat dalam percakapan, misalnya mengucapkan kata "panjang" anak cuma mengisyaratkan dengan tangannya, namun setelah diberikan latihan secara berulang-ulang, anak sudah mengeluarkan suaranya dalam mengucapkan kata. Sekarang anak sudah mengeluarkan suaranya, memahami tulisan atau kata. Begitu juga untuk tema dua (kebersihan lingkungan) pada awalnya anak masih menggunakan bahasa isyarat, dalam menyebutkan nama "sapu lidi" dengan cara seperti orang menyapu halaman. Tapi akhirnya anak sudah bisa mengucapkan kata dengan benar.

Kegiatan yang berulang-ulang pada siklus satu dengan dua tema, masih belum menampakkan perkembangan atau kemajuan pada saat latihan terkhir.Hal ini terlihat karena adanya dua anak tunarungu yang belum bisa melakukan percakarpan dan membaca ideovisual dengan menggunakan bahasa lisan, sehingga membutuhkan layanan individual.Dengan demikian perlu dilanjutkan pada siklus yang kedua.Berdasarkan hasil yang diperoleh pada siklus satu, peneliti dan guru kelas merancang kembali perencanaan yang lebih baik lagi.Yaitu memberikan layanan individual pada dua orang anak tunarungu yang masih mengalami hambatan dalam percakapan dan membaca ideovisual dengan menggunakan bahasa lisan, serta tidak lupa memberikan motivasi dan menggunakan media yang dapat menambah semangat anak tunarungu dalam mengucapkan bahasa lisan.Pada siklus dua ini sudah terlihat banyak kemajuan yang diperoleh anak tunarungu, baik dari ungkapan bahasa, pengucapan kosa kata, makna kata pengenalan struktur kalimat, intonasi dan kelancaran suara.

Perkembangan kemampuan berbahasa lisan anak dapat ditingkatkan, walaupun pada siklus satu ada dua anak yang berhasil.Namun diakhir siklus dua semua anak dapat mengembangkan kemampuan berbahasa lisan dengan baik.Perolehan kemampuan berbahasa lisan anak disajikan dalam bentuk angka (kuantitatif) namun merupakan konversi dari nilai kualitatif yang diperoleh dari 20 kali pertemuan. Cara memperolh nilai kuantitatif adalah dengan cara memberi bobot 4 yang nilai baik, 3 untuk nilai sedang dan 2 untuk nilai kurang. Sebagaimana diketahui bahwa anak tunarungu mengalami hambatan dalam komunikasi dengan orang lain. Hal ini merupakan pengaruh ketunarunguan yang disandangnya, sehingga anak mengalami hambatan dalam perkembangan bahasa dan bicara.

Jika dikaitkan dengan kajian teori yang ada, bahwa penggunaan Metode Maternal Reflektif dapat meningkatkan kemampuan berbahasa lisan anak tunarungu sedang kelas rendah V SLB Karakter Mandiri Bukittinggi.Berdasarkan kenyataan yang peneliti temukan, maka teori tersebut dapat menunjang hasil penelitian. Kemampuan berbahasa lisan anak tunarungu sedang kelas dasar V SLB Karakter Mandiri Bukittinggi dapat ditingkatkan melalui penggunaan Metode Maternal Reflektif yaitu percakapan dari hati ke hati dan percakapan membaca ideovisual, dilengkapi dengan media yang dapat menunjang dan memotivasi anak dalam melakukan percakapan, seperti gambar, miniatur benda model, benda asli, dan kartu kata. Namun di samping penggunaan media juga perlu diberikan layanan individual bagi anak yang mengalami kesulitan berbahasa lisan.

Pada siklus satu dan dua terungkap bahwa kemampuan berbahasa lisan telah sesuai dengan tujuan penelitian, dan hasilnya sudah dapat menggambarkan peningkatan kemampuan berbahasa lisan anak tunarungu.Hasil penelitian menunjukkan adanya peningkatan kemampuan berbahasa lisan anak tunarungu sedang kelas dasar V SLB Karakter Mandiri Bukittinggi dengan menggunakan Metode Maternal Reflektif. Adapun upaya yang dilakukan dalam melatih kemampuan berbahasa lisan anak tunarungu yaitu sebagai berikut:

a. Pemberian layanan individual bagi siswa yng mengalami kesulitan berbahasa lisan.

b. Pemberian motivasi dan penguatan, seperti : acungan jempol, bagus, elusan, tepuk pundak, dan lain-lain.

c. Penggunaan media yang bervariasi untuk menunjang kelancaran berbahasalisan anak tuanrungu. 


\section{SIMPULAN DAN SARAN}

Berdasarkan Hasil Penelitian pada Bab IV anak tunarungu selama dilatih ada setiap siklus belum dinyatakan berhasil dengan baik. Anak tunarungu setelah diberikan pelatihan berbahasa lisan dengan menggunakan Metode Maternal Reflektif dilakukan dengan menggunakan dua siklus. Dalam pelaksanaan silkus pertama anak tunarungu masih mengalami hambatan dalam percakapan dan membaca ideovisual dengan menggunakan bahasa lisan. Karena pada siklus pertama belum berhasil melatih anak untuk berbahasa lisan maka peneliti melanjutkan kegiatan pelatihan dapa siklus kedua dengan tema yang sama. Berdasarkan siklus kedua yang dilakukan beberapa tidakan anak tunarungu sudah menampakkan kemajuannya dalam berbahasa lisan.

Adapun upaya yang dilakukan dalam melatih kemampuan berbahasa lisan anak tunarungu adalah (1) Pemberian layanan individu bagi siswa yang mengalami kesulitan berbahasa lisan, (2) Pemberian motivasi dan penguatan seperti acungan jempol, kata bagus, elusan dan lain-lain, (3) Pengguanaan media yang bervariasi untuk menunjang dan membantu kelancaran berbahasa lisan anak tunarungu.

Berdasarkan hasil penelitian diberikan saran bahwa guru hendaknya menggunakan Metode Maternal Reflektif sebagai salah satu alternatif dalam upaya meningkatkan kemampuan berbahasa lisan anak tunarungu, guru supaya lebih meningkatkan frekuensi latihan berbahasa lisan secara terus menerus, agar siswa lebih terbiasa dalam berbahasa lisannya, guru hendaknya pada proses belajar mengajar melayani anak secara individual agar anak mampu berbahasa lisan dengan baik, kepala Sekolah hendaknya memberikan bimbingan, dukungan dan pembinaan pada guru agar dapat meningkatkan kemampuan berbahasa lisan, pada steakholden mampu bekerjasama dengan guru dan kepala sekolah demi peningkatan kualitas pembelajaran untuk anak.

\section{DAFTAR RUJUKAN}

Cecilia Susiloyuwati (1990) Metode Percakapan yang Reflektif dalam Hubungannya dengan Pelaksanaan Pengajaran di SLBB. Makalah. Jakarta. KKPLBIKIP

Fajri, R. A. S. (2015). Problematika Kemampuan Berbicara Bahasa Arab Mahasiswa Jurusan Pendidikan Bahasa Arab Fakultas Ilmu Tarbiyah dan Keguruan UIN Sunan Kalijaga Yogyakarta Tahun Akademik 20142015 (Doctoral dissertation, Universitas Islam Negeri Sunan Kalijaga).

Fitrianingsih-Nim, E. N. I. (2011). Upaya Pembimbing Dalam Meningkatkan Percaya Diri Anak Tuna Rungu di SLB PGRI Kecamatan Minggir Kabupaten Sleman (Doctoral dissertation, UIN Sunan Kalijaga Yogyakarta).

Greenwood, D. J., Whyte, W. F., \& Harkavy, I. (1993). Participatory action research as a process and as a goal. Human Relations, 46(2), 175-192.

Hasanah-Nim, U. S. W. A. T. U. N. (2010). Hubungan antara Ketaatan Beragama dengan Rasa Malu Bagi Anak Cacat Fisik di SLB Ma'arif Pucung Rejo Muntilan (Doctoral dissertation, UIN Sunan Kalijaga Yogyakarta).

Hernawati, T. (2007). Pengembangan Kemampuan Berbahasa dan Berbicara Anak Tunarungu. Jurnal JASSI_anakku, 7(1), 101-110.

Kemmis, S., McTaggart, R., \& Nixon, R. (2013). The action research planner: Doing critical participatory action research. Springer Science \& Business Media.

Khobir, A. (2013, May). Upaya Mendidik Anak Melalui Permainan Edukatif. In Forum Tarbiyah (Vol. 7, No. 2).

Lani Gunawan dan Cecilia Susiloyuwati (2000) Penguasaan Bahasa Anak Tunarungu.J akarta. Yayasan Santirama.

Lisa, A. Y. (2012). Efektivitas Media Flanelgraph untuk Meningkatkan Kemampuan Operasi Penjumlahan Bagi Tunarungu. E-JUPEKhu, l(2).

Mertler, C. A. (2008). Action research: Teachers as researchers in the classroom. Sage.

Pujiwati, S. (2012). Meningkatkan Pemahaman Kosakata Benda Anak Tunarungu Melalui Metode Maternal Reflektif di Kelas D II B di SDLBN Tarantang Lima Puluh Kota. Jurnal Pendidikan Luar Biasa.

Putri, Y. M. (2014). Strategi Guru dalam Membelajarkan Pecahan bagi Siswa Tunarungu Kelas VB di SLB-B Negeri Salatiga (Doctoral dissertation, Program Studi Pendidikan Matematika FKIP-UKSW).

Savitri, V. (2016). Tipe Kesalahan Penulisan dan Pengucapan Bahasa Indonesia Siswa Tunarungu dalam Pembelajaran Menyimak di SMPLB Bina Wiyata Putra Situbondo.

Setyawati, R. (2013). Bahasa Sebagai Sarana Belajar Dan Berpikir.

Setyono Bambang (1998) Terapi Wicara untuk Praktisi Pendidikan dan Kesehatan.Jakarta. 
Siti Walidatul, A. (2014). Penerapan Metode Maternal Reflektif (MMR) dalam Pembelajaran Pendidikan Agama Islam Bagi Anak Tunarungu di SDLB B Yakut Purwokerto Banyumas (Doctoral dissertation, IAIN Purwokerto).

Somad Pamanarian dan Hemawati Tati (1995).Ortopedagoaik Anak Tunarungu.Jakarta Depdikdud.

Stringer, E. T. (2008). Action research in education. Upper Saddle River, NJ: Pearson Prentice Hall.

Suci, E. R. (2013). Pengaruh Model Pembelajaran dan Tipe Kepribadian terhadap Hasil Belajar Bahasa Inggris Siswa SMP Swasta Al Washliyah Ampera II Medan Helvetia (Doctoral dissertation, UNIMED). Suyatno (1997). Podoman Pelaksanaan Penelitian Tindakan Kelas Bagian ke 1.Yokyakarta, Dirjen DIKTI.

Virlia, S., \& Wijaya, A. (2015). Penerimaan Diri pada Penyandang Tunadaksa. In Seminar Psikologi dan Kemanusiaan Pscyhology Forum UMM (pp. 372-377).

Yuliana, D. W., \& Supraptono, E. (2016). Multimedia Interaktif Menyimak Cerita tentang Peristiwa di Sekitar untuk Siswa Tunarungu. Jurnal Penelitian Tindakan Kelas, 17(1). 